\title{
Knowledge, attitudes and practices on Schistosomiasis in sub-Saharan Africa: a systematic review
}

\author{
Hlengiwe Sacolo ${ }^{1 *} \mathbb{D}$, Moses Chimbari ${ }^{2}$ and Chester Kalinda ${ }^{1}$
}

\begin{abstract}
Background: Schistosomiasis remains a global health problem with an estimated 250 million people in 78 countries infected, of whom $85 \%$ live in Sub-Saharan Africa. Preventive chemotherapy remains the key public health strategy to combat schistosomiasis worldwide. Recently the WHO emphasized on the use of integrative approaches in the control and elimination of schistosomiasis. However, a detailed understanding of sociocultural factors that may influence the uptake of the intended health activities and services is vital. Thus, our study sought to understand the knowledge, attitudes, perceptions, beliefs and practices about schistosomiasis in various communities in Sub-Saharan Africa.

Methods: A systematic search of literature for the period 2006-2016 was done on Medline, PubMed, CINAHL, Psych info and Google Scholar using the following key words "Schistosomiasis, S. mansoni, S. haematobium, knowledge, attitudes, perceptions, beliefs and practices in Sub-Saharan Africa" in combination with Bolean operators (OR, AND). In this context, we reviewed studies conducted among school children, community members and caregivers of preschool children. Thematic analysis was utilised for the overall synthesis of the selected studies. This was done after reading the articles in depth. Themes were identified and examined for similarities, differences and contradictions.

Results: Gaps in schistosomiasis related knowledge and sociocultural barriers towards the uptake of preventive and treatment services among communities in Sub-Saharan Africa were identified. In addition to limited knowledge and negative attitudes, risky water related practices among community members, school children and caregivers of preschool children were identified as key factors promoting transmission of the disease.

Conclusion: The study concluded that a comprehensive health education programme using contextual and standardised training tools may improve peoples' knowledge, attitudes and practices in relation to schistosomiasis prevention and control. Findings also highlight the significance of including caregivers in the planning and implementation schistosomiasis control programs targeting pre-school children.
\end{abstract}

Keywords: Schistosomiasis, S. mansoni, S. Haematobium, Knowledge, Attitudes, Perceptions, Beliefs, Practices, Sub-Saharan Africa

\section{Background}

Schistosomiasis, widely known as bilharzia, remains a public health problem in several parts of the world, particularly in Africa. Despite numerous programs aimed at combatting the global prevalence, infection rates remain high, particularly in sub Saharan Africa which accounts for over $85 \%$ of people living with schistosomiasis in a

\footnotetext{
* Correspondence: hnsacolo@gmail.com

${ }^{1}$ School of Nursing and Public Health, College of Health Sciences, University

of KwaZulu-Natal, Howard Campus, Durban, South Africa

Full list of author information is available at the end of the article
}

population that only constitutes $13 \%$ of the world's population [1]. Worldwide, there are six species of schistosomes that affect human beings [2]. Schistosoma intercalatum, Schistosoma mekongi, Schistosoma japonicum and Schistosoma guineesis are localized to specific settings whilst, Schistosoma haematobium and Schistosoma mansoni are wide spread [3]. Of all these species, the most prevalent in Sub-Saharan Africa are S. haematobium and S. mansoni which cause urogenital and intestinal schistosomiasis, respectively [4]. 
The scale and trend of the disease burden in SubSaharan Africa varies considerably, with poverty stricken and marginalized communities being the most affected [5]. These populations have low socio-economic status with limited access to clean water and adequate sanitation. The perpetual progression of schistosomiasis in this region is coupled with devastating and long-lasting effects. For instance, even though schistosomiasis is preventable and treatable, if left untreated it can lead to debilitating and irreversible clinical complications such as liver and spleen enlargement, bladder ulceration and deformities, infertility and kidney blockage [6, 7]. Across Sub-Saharan Africa, children, women and those working in contact with natural water bodies continue to be at greater risk [8,9]. Researchers suggest that success in schistosomiasis prevention among these groups has the potential to reduce the rate of transmission among the general population and ultimately reduce the population prevalence of schistosomiasis [10]. The increased risk of infection among such groups is true for all countries in Sub-Saharan Africa and is attributed mainly to risky water practices, poor sanitation, lack of knowledge, negative attitudes and beliefs about schistosomiasis. Among women, low educational status has been found to be an additional predictor of infection [11].

Another explanation for the heightened prevalence of schistosomiasis can be drawn from recent findings pointing to the exclusion of under-fives from MDA programs and subsequently care givers from health education campaigns in endemic areas [12, 13]. Most schistosomiasis educational programs target school going children because they are easy to reach [14]. This however excludes community members including caregivers who may unknowingly predispose preschool children entrusted to their care to schistosomiasis infection. The positive influence of comprehensive knowledge, positive attitudes and practices on effective prevention and control of parasitic infections is well established [15-17]. The degree of such influence however varies according to community settings and programs implemented. This highlights the need for relevant and vibrant health education programs addressing sociocultural barriers towards sustained schistosomiasis prevention and control in the African context.

Previous WHO recommendations mainly supported the regular treatment of at least $75 \%$ of school aged children at risk as basis of control [18]. That eventually resulted in the skewed focus on funding, schistosomiasis control programs and research on school going children aged 6-15 years old whilst depriving the younger and older ones of such benefits. In 2012 however, the World Health Assembly adopted resolution (WHA 65.21) that called for the elimination of schistosomiasis through the use of integrated control strategies inclusive of all vulnerable groups [8]. This resolution seems to be in line the Supply-Enabling Environment-Demand (SEED) programming model [19] which asserts that disease elimination may be possible through simultaneous implementation of the following tasks: (i) provision of timely treatment and quality service delivery, (ii) promotion of positive health seeking behaviour, improved knowledge, attitudes and practices that ensure sustainability of control efforts; and (iii) provision of an enabling environment for effective service delivery that includes the establishment of national policies, guidelines, programs and a community environment that promotes disease elimination. The Supply-Enabling Environment-Demand (SEED) programming model stems from the law of supply and demand and the enabling environment theory which have been used by numerous studies across disciplines, population groups and countries [20-25]. Given the broadness in scope of the key concepts used in the model and its consideration of social norms and behaviour change, it is easily adapted to give guidance to programs in various fields of study. It has been used recently among children to guide child protection programs and to generate evidence on the extent to which children with disability access school education in eastern and Southern Africa [26].

The WHO encourages countries to adopt policies and programs focusing on eliminating schistosomiasis rather than just controlling its morbidity, thus the need to integrate MDA programs with primary health care interventions such as effective health education programs [18]. Essentially, health education should be the heartbeat of all health promoting interventions in order to yield sustainable positive changes. Designing such programs however warrants the understanding of existing knowledge, attitudes, perceptions, beliefs and practices about schistosomiasis in endemic communities. Our review therefore aimed at understanding the role of knowledge, attitudes and practices (KAP) in relation to schistosomiasis prevention and control in various communities in Sub-Saharan Africa. The review contributes to knowledge that will influence policy decisions in Southern Africa regarding the inclusion of under-five children in schistosomiasis treatment programs.

\section{Methods}

\section{Searching strategy}

We conducted a systematic review of literature using articles published between 2006 and 2016 because we wanted to assess what issues have been raised in the past 10 years so as to identify key research gaps for the work we intent carrying out on the subject matter. The literature search was done independently by two investigators (HS, CK) who searched for articles in various databases (Medline, PubMed, CINAHL, Psych info and Google 
Scholar), using the following key words "Schistosomiasis, S. mansoni, S. haematobium, knowledge, attitudes, perceptions, beliefs, and practices in Sub-Saharan Africa". Search terms used in this review were initially broad in scope in an attempt to cover a wide breadth of knowledge in answering the research question. After this, key word synonyms were identified and combined with key words to allow a more comprehensive search. The search used both 'free terms' and 'index terms' funnelled using the Bolean operators (OR, AND) and truncations. Our search was limited to articles published in English. We followed the PRISMA (Preferred Reporting Items for Systematic Reviews and Meta-Analyses) guidelines for conducting and reporting this systematic review.

\section{Study selection}

The review strategy was carried out in three stages. The first stage was identification of records through data base searching; the second stage involved the screening of abstracts by two authors in order to carefully select literature that met the inclusion criteria and the final stage was assessment for eligibility. The process followed is illustrated in the PRISMA flow diagram (Figure 1). Twenty seven full articles were deemed eligible for the review. Studies were included if they were published between 2006 and 2016, conducted in countries within Sub-Saharan Africa provided they focused on awareness, knowledge, attitudes, perceptions, beliefs and practices on schistosomiasis. Papers selected were scrutinised to find the best available evidences to support the study purpose.

\section{Quality assessment}

Quality appraisal was assessed using a critical appraisal tool for assessment of cross-sectional studies modified from Downes, Brennan [27]. The total quality score was computed for each study using the following indicators which were also in line with the study objectives: (1) clear definition of objectives and aims; (2) study design appropriate for the stated aims; (3) sample size justified; (4) target population clearly defined (appropriate population base/unbiased sampling) (5) risk factor and outcome variables measured correctly using instruments that had been trialled, piloted or published previously; (6) methods (including statistical methods) sufficiently described to enable them to be repeated; (7) results for analysis described in the methods presented; (8) authors discussions and conclusions justified by results; (9) limitations of the study discussed; (10) ethical approval or consent of participants attained. Answers were scored 0 and 1 for 'No' and 'Yes', respectively. Total scores varied between 0 and 10 where $1-4=($ Low $) ; 5-7=($ Moderate $)$ and $8-10=($ High $)$. The total quality scores in this study ranged from moderate to high across studies (Additional file 1).

\section{Data abstraction}

For studies that were identified and selected for inclusion in the review, we extracted information about the

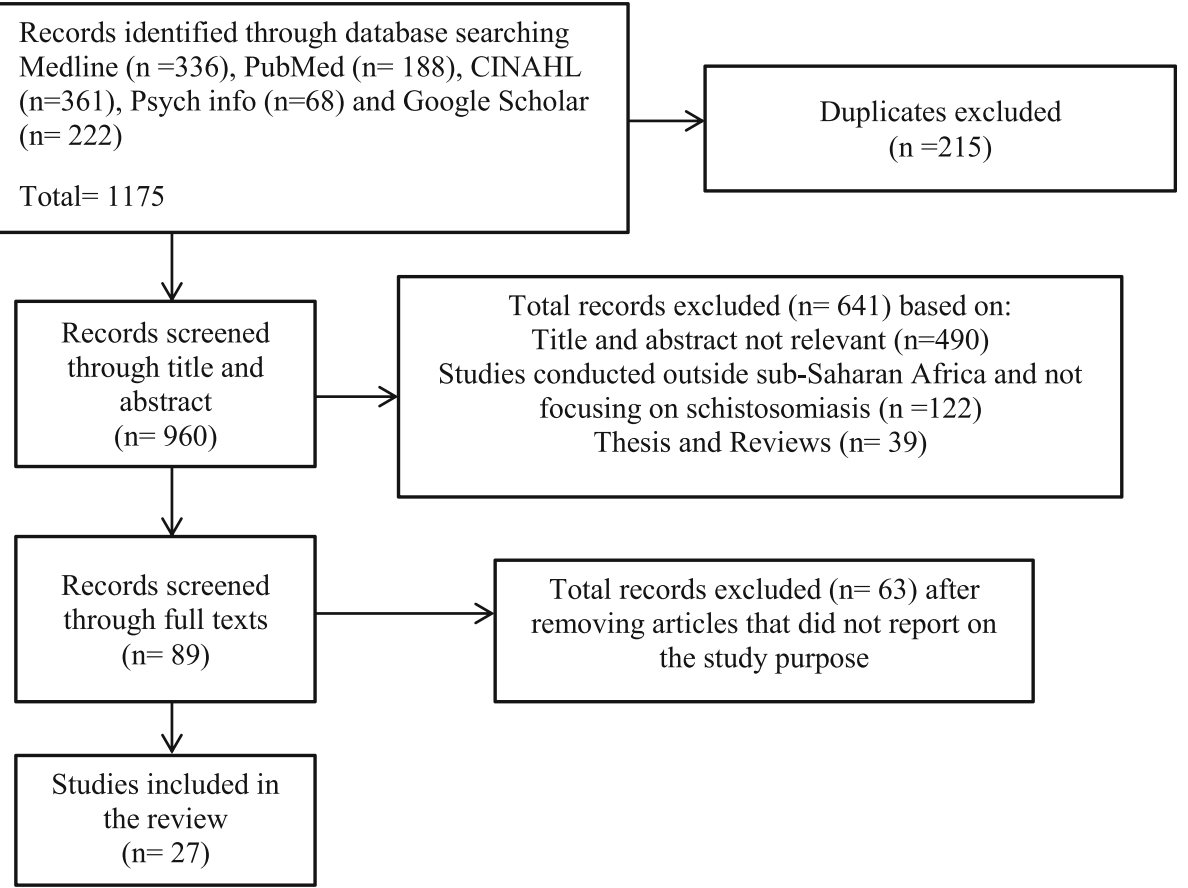

Fig. 1 PRISMA flow diagram 
study: first author, year of publication, study objectives, study population, study location and summary of the findings. Studies were presented in three categories; those conducted among (1) community members, (2) caregivers and (3) school children. Thematic analysis was utilised for the overall synthesis of the selected studies. This was done after reading the articles in depth. Themes were identified and examined for similarities, differences and contradictions.

\section{Results}

For this study, 1175 articles studies were initially identified from the five data bases. The articles were screened and 960 were retained after 215 duplicated articles were removed. Of those articles, 641 were excluded for the following reasons (1) title and abstract not relevant (2) not conducted in Sub-Saharan Africa (3) did not focus exclusively on schistosomiasis (4) were not peer reviewed articles. Only 89 articles were considered for full text reviewing. Out of these, 27 were retained and included in this review. The primary evidence base for these studies comprised of quantitative, qualitative and mixed method studies. Thematic analysis was utilised for the overall synthesis of the selected studies. This was done after reading the articles in depth. Themes were identified and examined for similarities, differences and contradictions.

Four major themes emerged from this review: (1) socio-demographic (2) knowledge and awareness on schistosomiasis (3) attitudes and beliefs related to schistosomiasis (4) Practices related to schistosomiasis prevention and control. The review also displays three categories of KAP studies. There were 18 community based KAP studies, 4 school based studies and 5 conducted among care givers of children aged 5 years and below. The studies synthesised in this review are from nine Sub-Saharan countries namely: Kenya $(n=5)$, Uganda $(n=4)$, Nigeria $(n=6)$, Mozambique $(n=1)$, Ghana $(n=3)$, Tanzania $(n=5)$, Malawi $(n=1)$, South Africa $(n=1)$ and Swaziland $(n=1)$. Table 1 summarises the papers.

\section{Knowledge and awareness about schistosomiasis}

Current findings indicated that schistosomiasis awareness ranged between 75 and 98\% [8, 28-38]. However, comprehensive knowledge on the signs and symptoms, transmission, prevention and treatment was observed to be low. Other studies further showed that participants confused the prevention and transmission of schistosomiasis with that of soil transmitted helminths (STH). For instance, several studies [28, 31, 38, 39] reported that the majority of participants suggested that schistosomiasis was transmitted through drinking contaminated water or eating contaminated food. Nine studies evaluated the impact of the health education component of MDA programs and reported increase in participants' knowledge, attitudes and practices related to schistosomiasis $[17,31,34,40-45]$.

\section{Attitudes, misconceptions, beliefs and perceptions}

The results from the review show that about 60\% (16/ 27) of the studies reported misconceptions regarding schistosomiasis prevention and control. The misconceptions that schistosomiasis was caused by drinking unclean water and eating contaminated food were reported by most studies across Sub-Saharan Africa [16, 28, 31, 33, 39, 46]. However, in Kenya, participants believed that schistosomiasis is caused by HIV [30, 47]. Furthermore, some participants mistook syphilis for schistosomiasis [31]. On the other hand, participants in Nigeria and Mozambique [32, 33] thought that schistosomiasis was transmitted through unprotected sex and sharing of toilets with infected people infected with schistosomiasis [29]. Urinating at $\mathrm{T}$-junctions of roads [17, 41] and witchcraft [32] were perceived as causes of schistosomiasis in Nigeria. Results from Uganda, Nigeria, and Mozambique suggest that the disease is believed to be hereditary, acquired during pregnancy or birth and thus considered a natural disease that could be outgrown with time [28, 32, 33, 36]. Additionally, the current study indicates that praziquantel was mistaken for family planning tablets strategically used by MDA programs to prevent people from having many children [34]. The drug was also perceived to be expensive [17, 30, 31], dangerous due to side effects $[28,40,42]$ and the efficacy was questioned by some respondents due to the reoccurrence of symptoms after treatment [32, 48]. These reasons contributed to poor health seeking behaviour with some respondents eventually resorting to the use of traditional medicine and spiritual interventions [28, 31].

\section{Practices on schistosomiasis prevention and treatment}

The results from the current study indicate that water related practices such as harvesting hippo grass, fishing, washing clothes, washing utensils, bathing and fetching water from rivers or streams and open air defaecation were observed to be risky behaviour practices that enhanced disease transmission [28-33, 37-39, 44, 46, $49,50]$. Results further indicate that the use of community gatherings, radios, posters and the involvement of local stake holders in schistosomiasis prevention campaigns were that most preferred health promotion strategies [34]. According to Adeneye et al. [17], community directed systems were more successful compared to primary health care centred and school based approaches. 


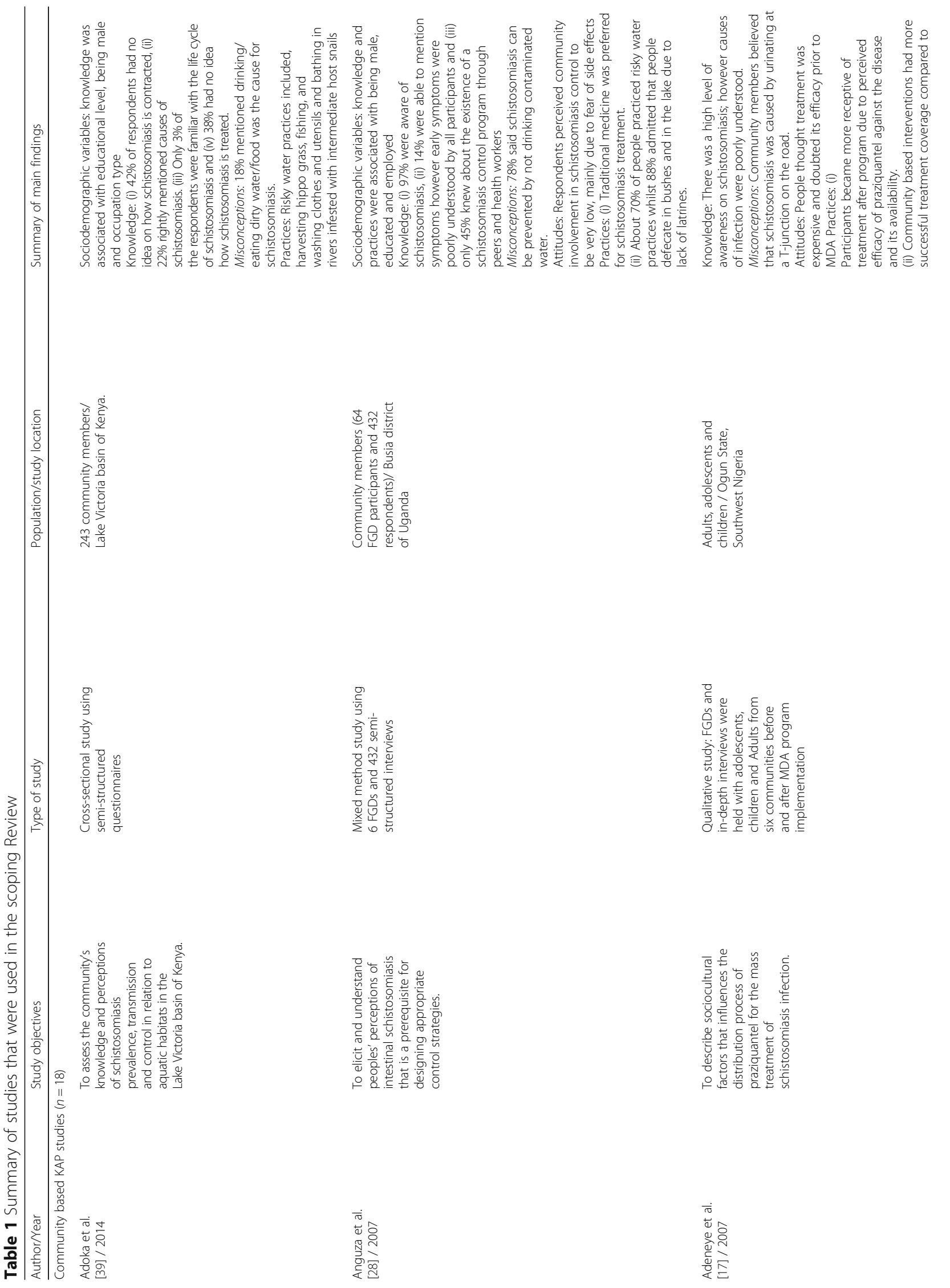




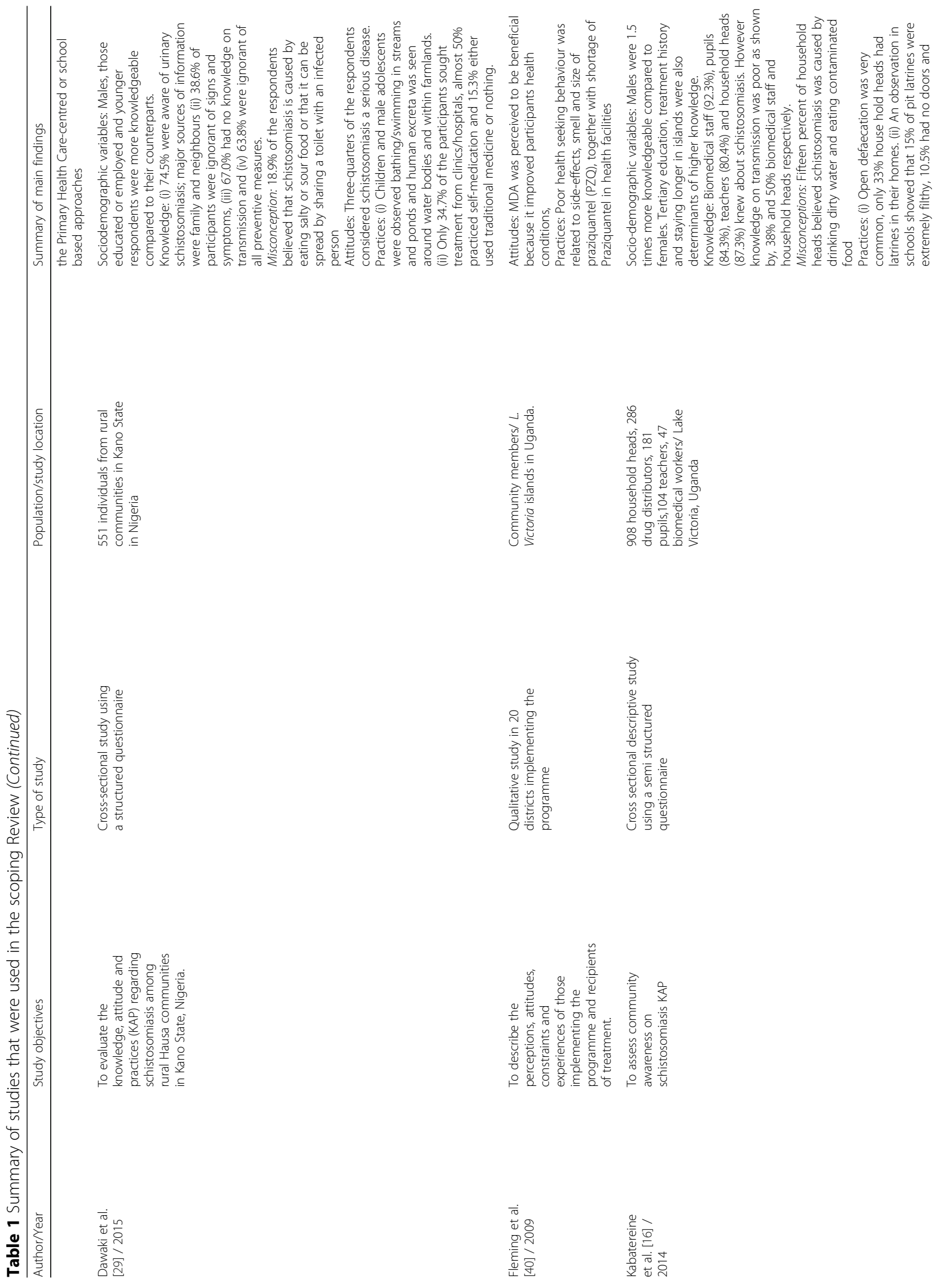




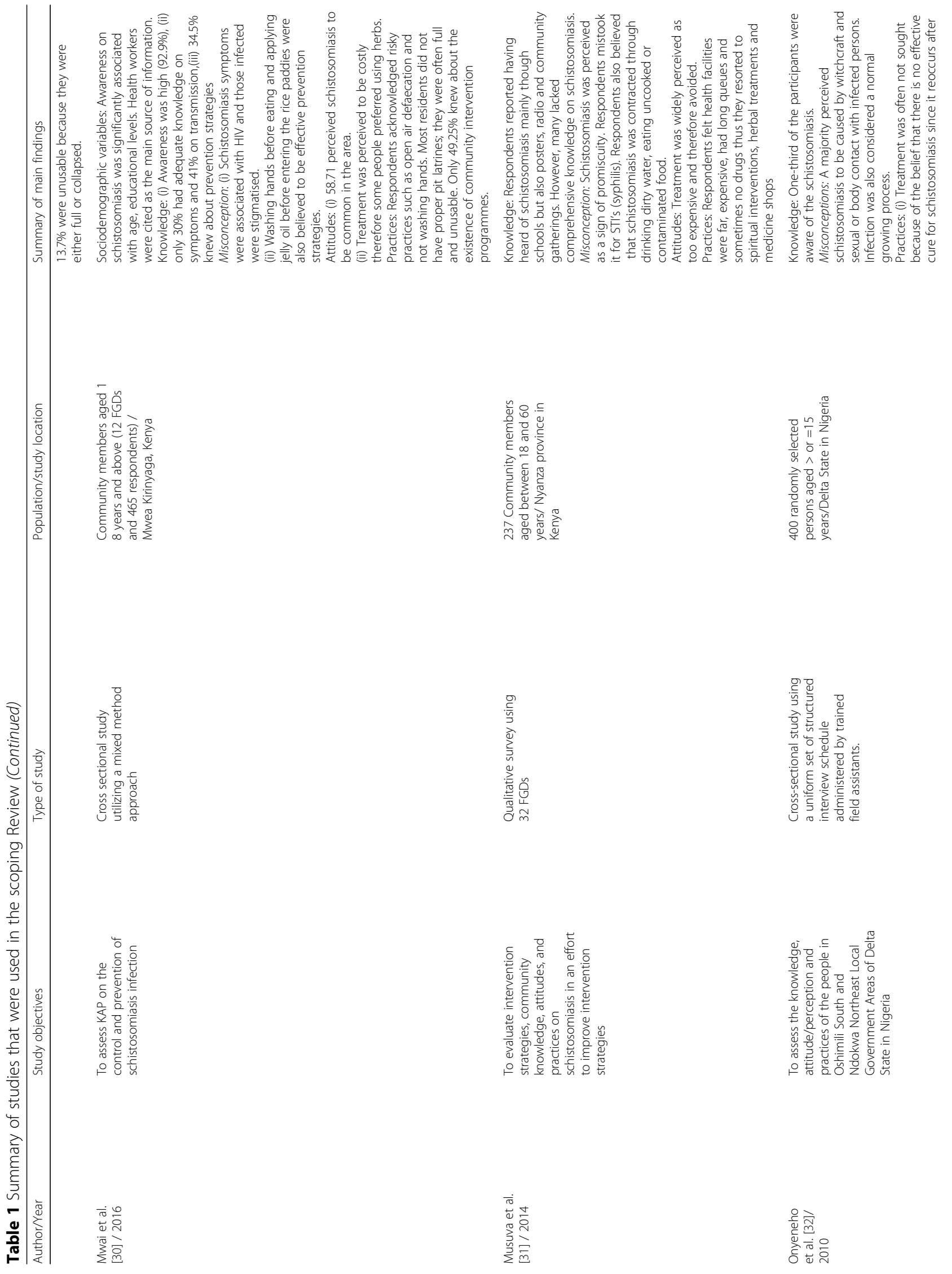




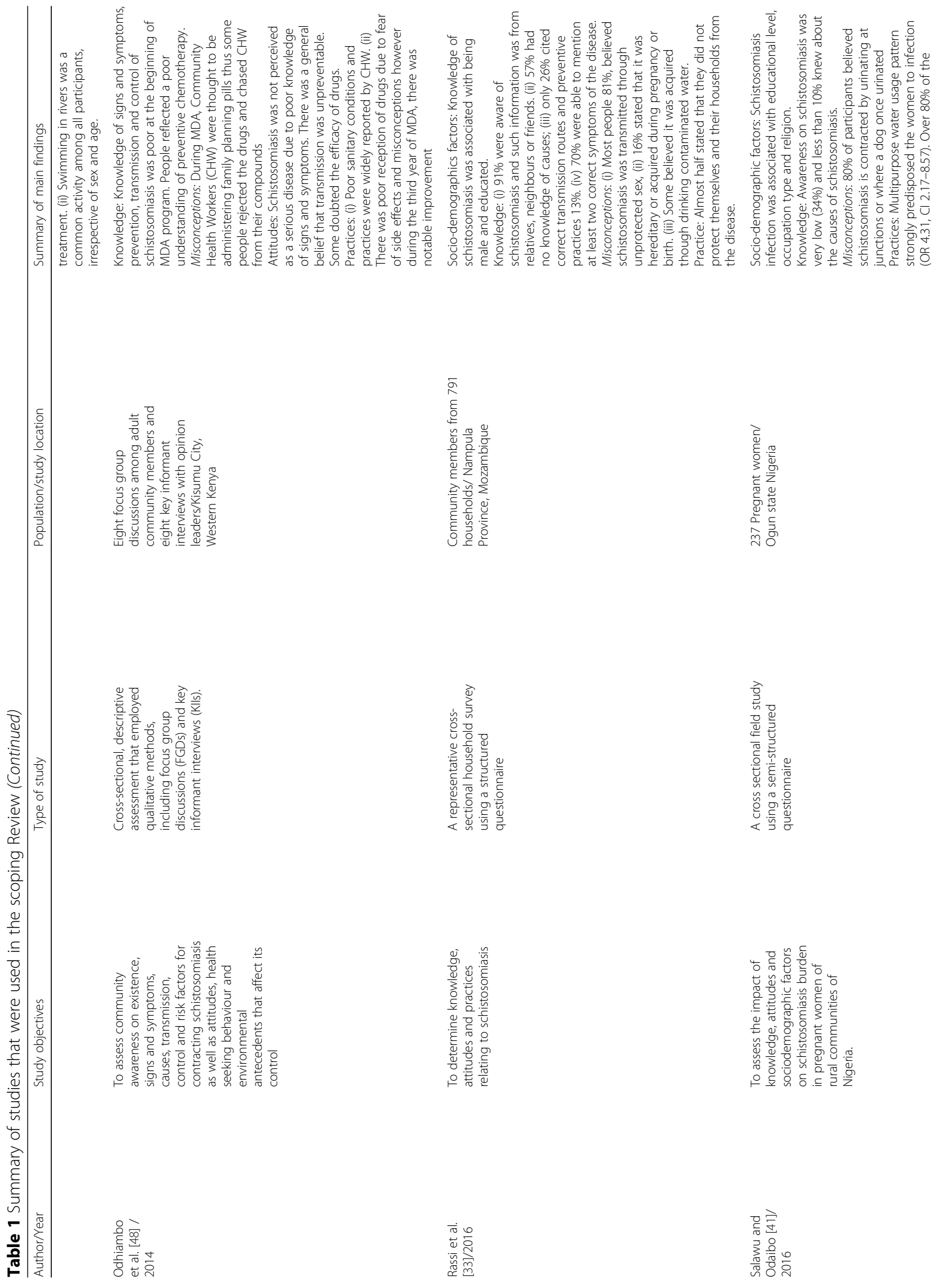




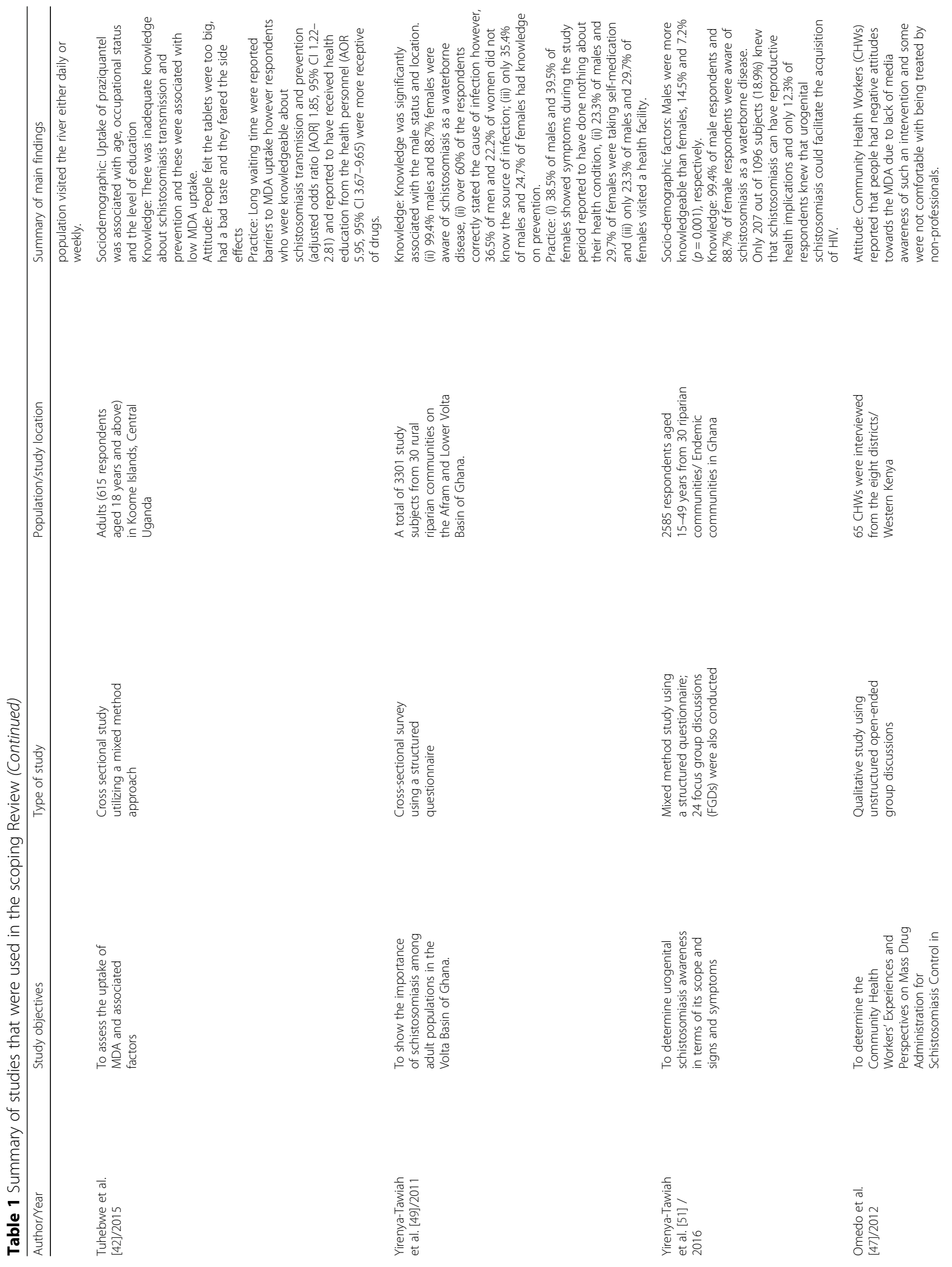




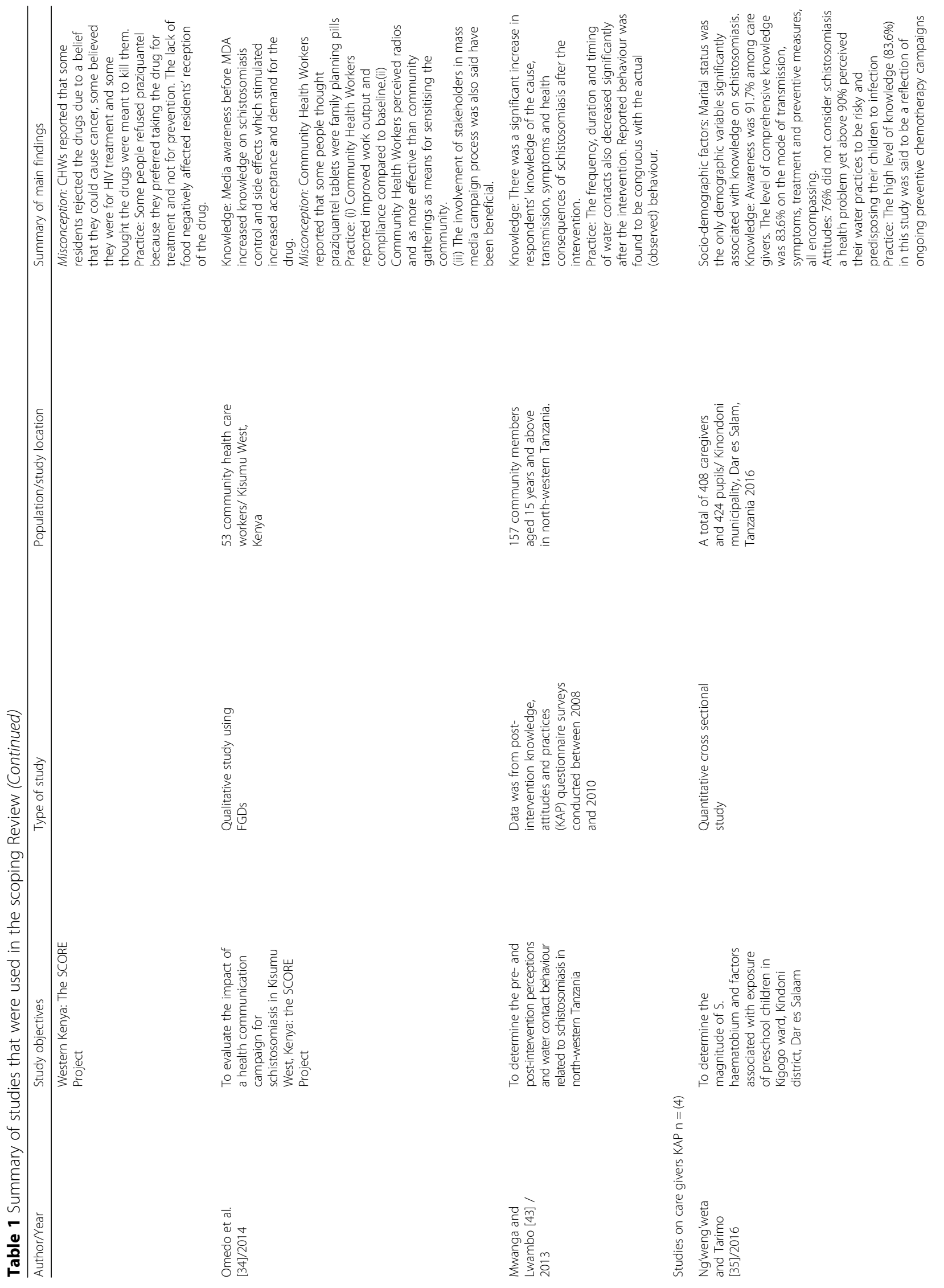




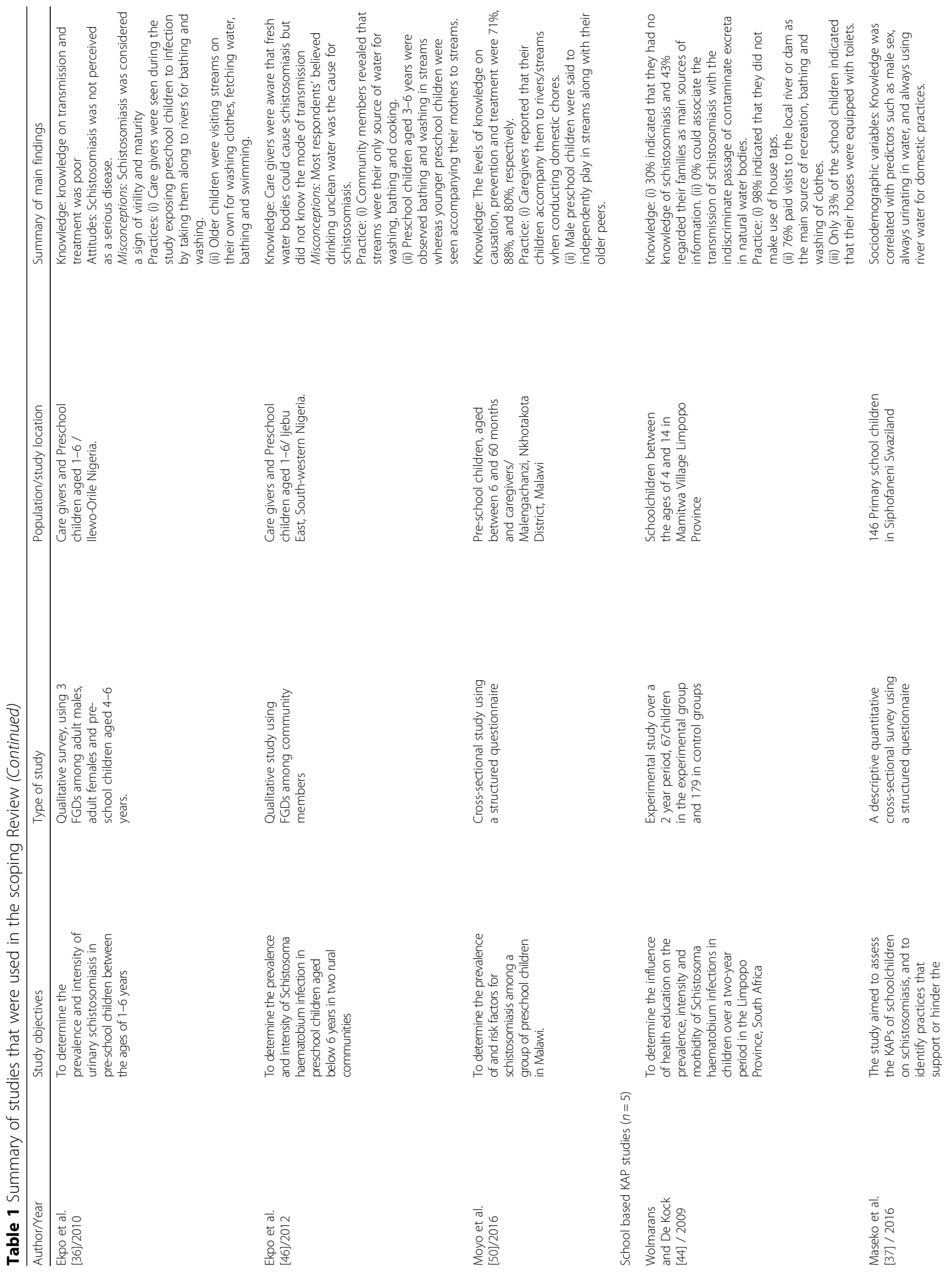




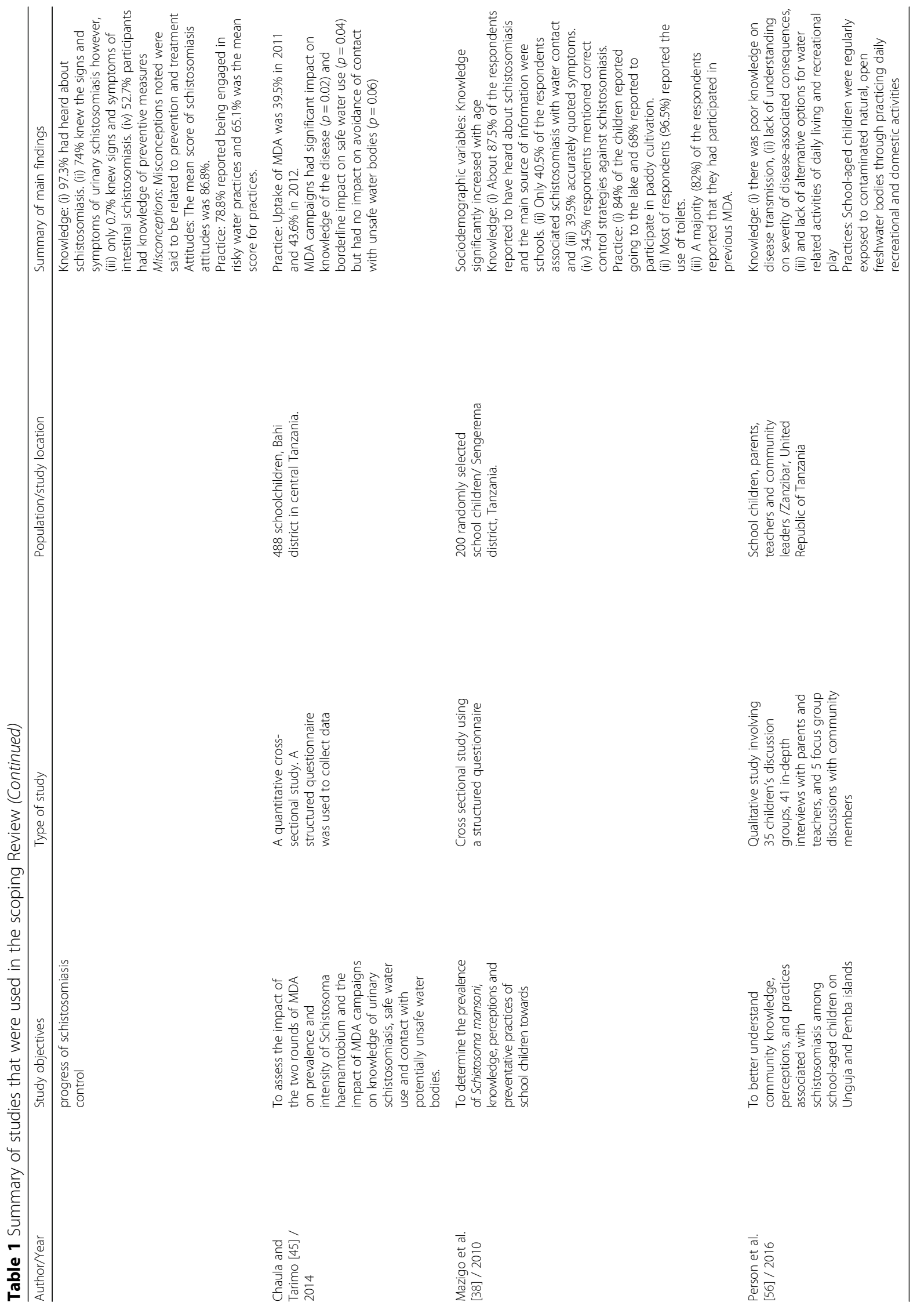




\section{Association between awareness, knowledge, attitudes and behaviour}

In this study, high levels of awareness were not congruent with high knowledge levels of the disease. Participants and respondents with higher levels of knowledge were more likely to present with better attitudes towards schistosomiasis prevention and treatment. Knowledgeable participants were also more receptive of treatment compared to those with poor schistosomiasis related knowledge. Misconceptions are said to have contributed to poor health seeking behaviour with some respondents eventually resorting to the use of traditional medicine and spiritual interventions $[28,31]$.

\section{Community, care givers and school based studies}

Results from this study show limited KAP across countries. However, studies from Tanzania [35] and Malawi [50] reported adequate knowledge shown by composite scores of 83.6 and $79.7 \%$, respectively. In Tanzania, the high level of knowledge was said to be a result of a MDA campaign which was ongoing at the time of the study. The exposure to freshwater bodies varied according to the study population. For instance, community members and care givers mainly visited streams and rivers for washing and bathing their young children while school children mainly contacted freshwater bodies during recreational activities such as swimming.

\section{Sociodemographic factors related to schistosomiasis KAP}

Results from the reviewed studies suggest that awareness and knowledge of schistosomiasis was poor among women and uneducated members of the community [16, 28-30, 33, 39, 41, 42, 49, 51]. In contrast, other studies observed that participants below the age of 20 were more knowledgeable and aware about schistosomiasis [29, 30, $37,42]$. With regards to studies conducted among care givers in Tanzania, Ng'weng'weta and Tarimo [35] found that married women had significantly higher levels of schistosomiasis related knowledge compared to unmarried women. Nigerian caregivers were observed washing in the company of younger preschool children while those aged 3 to 6 years were found to be more adventurous, bathing and swimming independently $[36,46]$ thus increasing their exposure to risk of schistosoma contraction. Such findings are in consonant with Moyo and Changadeya [50] who concluded that in Malawi, 4 year old preschool children were 5.26 times at higher risk of contracting urogenital schistosomiasis infection compared to 2 year old preschool children. Results from other studies also indicated that religion [41]; schistosomiasis treatment history $[5,30]$ and occupation $[28,29,39,41,42]$ were associated with better knowledge and practices.

\section{Discussions}

This review applied a systematic approach to assess the knowledge, attitudes and practices on schistosomiasis in Sub-Saharan Africa. The study encompassed KAP studies conducted among community members, school children and care givers of preschool children. Such a combination of studies from diverse settings embody the diverse nature of findings, considering that Sub-Saharan Africa is reasonably heterogeneous in terms of sociocultural, economic and demographic profiles which may impact on schistosomiasis control. The study built on the existing literature highlighting salient socio-cultural influences that form barriers towards the prevention and control of schistosomiasis.

\section{Factors hindering schistosomiasis prevention and control The influence of knowledge levels}

The results obtained from the studies reviewed indicate lack of comprehensive knowledge relating to schistosomiasis transmission, prevention and control. This is unfortunate considering that the proficiency of correct, comprehensive knowledge in promoting healthy attitudes and protective behaviour has been long established [52, 53]. Adoka et al. [39] observed that only $3 \%$ of respondents in Lake Victoria basin could relate schistosomiasis to snails. The reduction in the levels of knowledge among the respondents may be attributed to reduced community education [54]. According to Inobaya et al. [15], community based education may lead to behavioural change like avoidance of contact with infested water bodies and contamination of the environment with faeces. However, for behavioural change to be feasible, health education should be coupled with the provision of safer water sources and basic sanitation $[16,29]$. Other authors argue that knowledge does not directly translate into behaviour change but it promotes positive attitudes towards the behaviour in question [15, 19]. Notwithstanding this, the role of comprehensive knowledge as a behaviour change agent is well established.

Previous studies have observed that lower levels of knowledge on schistosomiasis and other NTDs is often accompanied by increased levels of misconceptions which may lead to poor prevention practices [34, 42, 45]. Then current study suggests that preventive chemotherapy programmes are likely to be successful if they incorporate a comprehensive health education component on schistosomiasis prevention and control [17, 28, 40]. Another issue raised by previous authors is the lack of a standard definition of comprehensive schistosomiasis related knowledge across countries [10,52]. In this review we observed variation in terms of the scope of health education messages. For instance, very few studies reported on information pertaining to the life cycle and types of schistosomiasis [28, 39]. We have further observed that 
participants with higher knowledge were more likely to adopt protective behaviour towards schistosomiasis infection $[31,50,55]$. Such findings propose the use of standardised context specific training manuals appropriately designed to suit school children and community members in order to limit variation in health education messages.

\section{Socio-demographic determinants}

Age, gender and level of education were widely shown to have an impact on schistosomiasis knowledge and practices. The impact of these social determinants in addition to socioeconomic factors on health promotion interventions at individual, community and organizational levels have been reported $[14,55]$. The current study observed that uneducated women were more vulnerable to schistosomiasis infection due to their daily water related house chores coupled by poor knowledge on preventive and control measures. In a study conducted by Ng'weng'weta and Tarimo [35], marital status was associated with knowledge indicating that married couples were more likely to share health related knowledge. Older community members were more prone to poor schistosomiasis related knowledge compared to school going children [33, 36, 46, 56]. Nevertheless, risky water contact practices such as swimming were more common among school going children $[16,37,45,48]$. These findings suggest that an understanding of the socio-demographic and socio-economic profiles of communities may contribute to implementation of effective programmes aimed at controlling schistosomiasis.

Only 12 of all the studies reviewed reported on the influence of sociodemographic variables on schistosomiasis knowledge. Eight of the 12 studies consistently reported a significantly higher level of knowledge among males compared to females. In a study conducted by Ng'weng'weta and Tarimo (2016) however marital status was the only sociodemographic variable significantly associated with knowledge. In a study conducted by Mazigo et al. [2010] males were more exposed to risky water practices such as fishing compared to females and studies conducted in Kenya and Nigeria discovered that fishermen and farmers had better knowledge on schistosomiasis [28, 39]. Furthermore, Tuhebwe et al. [42] found that being a fisherman was positively associated with the increased uptake of Praziquantel during their mass drug administration.

\section{Attitudes and misconceptions}

Acquisition and dissemination of the right information is key in the reduction of schistosomiasis infection risks. Some authors [28, 53], suggested that the right information equips people with knowledge on the schistosomiasis transmission cycle. It also enables them to adopt safer water and sanitary practices. The reviewed studies suggest that in rural communities, health related messages are shared among friends and neighbours. These massages, if not explained properly, may lead to misconceptions and promote superstitious beliefs as observed by several authors [16, 17, 40, 49]. Such beliefs may affect the utilization of health services leading to delayed diagnosis and treatment [14]. Sixty percent $(60 \%)$ of the studies reviewed indicated that schistosomiasis was a sexually transmitted infection [29, 30, 32, 33, 47]. Such findings are consistent with previously reported findings $[1,5]$. These studies concluded that misconceptions regarding schistosomiasis and STH transmission were rampant among people living in endemic areas. The confusion regarding information on the mode of transmission relating to schistosomiasis and STH suggests the lack of integrative approaches towards schistosomiasis and STH programming. Previous findings have highlighted the importance of addressing social and environmental issues in order to achieve effective comprehensive control programs for helminthic infections [57].

\section{Practices associated with risks of infection}

Our study observed that methods employed by caregivers may predispose their children to schistosomiasis infection $[13,36,50]$. This is because water contacts activities such as bathing and washing may be performed in the company of infants and preschool children [36, 46]. The vulnerability of and preschool children is substantiated by evidence from studies conducted in Mali [58], Niger [13], Sudan [59], Uganda [60] and Zimbabwe [61] where high prevalence of schistosomiasis among preschool children ranged from 18 to $63 \%$. The importance of adopting sound strategies that empower community members to take relatively simple measures to prevent disease, protect their health and adhere to treatment is well described in literature [62, 63]. However, the work conducted in Kenya [30] and South Africa [44] suggest that the effect of poor knowledge on disease prevention practices can be mitigated by the presence of basic environmental and health services, such as the availability of safer sources of water supply and adequate sanitation. Studies conducted in Nigeria, Malawi and Swaziland [13, 37, 50] reflected that knowledge alone may not be enough to influence healthy practices. The authors further noted the persistence of risky sanitary and water related practices among care givers and school children with comprehensive knowledge on schistosomiasis. This suggests the need for an integrative approach for effective prevention and control of schistosomiasis. This can be achieved through integrated implementation of MDA with proper sanitation education programmes, provision of safe water supply and health education for effective schistosomiasis control. 
Towards schistosomiasis prevention and control

The current findings highlight the significance of health education as a key component of the schistosomiasis control programs $[31,51,55]$. This is because such programs are said to improve awareness, knowledge and uptake of preventive chemotherapy [17, 31, 34, 40, 42, $45,47,48]$, thus increasing the success of MDA programmes. The major limitation of schistosomiasis control programs in endemic countries is the inadequate coverage and sustainability of programmes which is not only due to poverty but also to social, cultural, and political forces that remain understudied [5]. Previous epidemiological studies have advocated for the adaptation of prevention and control strategies to people's livelihoods in order to achieve high levels of MDA uptake and adoption of protective behaviours towards schistosomiasis prevention and control $[1,55]$. It is therefore imperative to consider the influence of social, cultural and cognitively rooted influences on health risk behaviours in schistosomiasis prevention and control strategies.

\section{Limitations}

Limitations of the study could be related to the lack of a standard definition for awareness, knowledge, attitudes and practices and the skewed focus on articles published in English. The review however, attempted to give a comprehensive description of studies conducted among community members, caregivers and school children even though few KAP studies were found under the two latter categories. Articles with richer descriptions may have been over-represented in the study only because they provided the required information. The review does not present quantifications to characterize the literature thus a significant portion of the decision-making, abstraction and interpretation is subjective. We therefore convened regular group discussions to evaluate our understanding of the subject throughout the review process.

\section{Conclusion}

In conclusion, the study suggests the need for changes in knowledge, attitudes and practices of people in relation to schistosomiasis prevention and control. Contextual and standardised training tools tailored for community and school based schistosomiasis control programs are of great necessity. Studies focusing on schistosomiasis among preschool children should not overlook the role that can be played by caregivers in protecting children from infection provided they are adequately empowered to do so. This review emphasises on the importance of incorporating a health education component to both community and school based MDA programs. Further research focused on evaluating the impact of existing control programs on the KAP and disease burden among beneficiaries of such programs is imperative.

\section{Additional files}

Additional files 1: Quality Assessment of individaul studies. This is a tool that was used for critical appraisal of the studies included in the review. This tool was modified from the initially developed by Downes and Brennan [27] (DOCX 23 kb)

\section{Abbreviations \\ HIV: Human Immunodeficiency Virus; KAP: Knowledge, Attitudes and Practices; MDA: Mass Drug Administration; NTD: Neglected Tropical Diseases; PRISMA: Preferred Reporting Items for Systematic Reviews and Meta- Analyses; SEED: Supply-Enabling Environment-Demand; STH: Soil Transmitted Helminths; STI: Sexually Transmitted Infections; WHA: World Health Assembly; WHO: World Health Organization}

\section{Acknowledgements}

The authors are grateful to MRC for having supported the student through the student scholarship. The authors further acknowledge the reviewers for their comments which improved the quality of the manuscript.

\section{Funding}

This work that was done leading to this manuscript was funded Medical Research Council of South Africa (MRC) through the student scholarship offered to HC. The funders had no role in designing this study, preparation of the manuscript and decision to have it published. Furthermore, the views, opinions, assumptions or any other information presented in this manuscript are solely those of the authors. We also acknowledge the precious inputs from the editors and the reviewers which helped improve the content and quality of the paper.

\section{Availability of data and materials}

No data was collected in this study. Therefore, data availability is not applicable.

\section{Authors' contributions}

HS and MC developed the concept. HS did literature searches, analysis and reporting. MC and CK guided the process of the literature search and manuscript writing. All the authors have read and approved the final article.

Ethics approval and consent to participate

Not applicable

Consent for publication

Not applicable

\section{Competing interests}

The authors declare that they have no competing interests.

\section{Publisher's Note}

Springer Nature remains neutral with regard to jurisdictional claims in published maps and institutional affiliations.

\section{Author details}

${ }^{1}$ School of Nursing and Public Health, College of Health Sciences, University of KwaZulu-Natal, Howard Campus, Durban, South Africa. ${ }^{2}$ College of Health Sciences, University of KwaZulu-Natal, Howard Campus, Durban, South Africa.

Received: 19 July 2017 Accepted: 14 December 2017

Published online: 18 January 2018

\section{References}

1. Boko PM, Ibikounle M, Onzo-Aboki A, Tougoue J-J, Sissinto Y, Batcho W, Kinde-Gazard D, Kabore A. Schistosomiasis and soil transmitted Helminths distribution in Benin: a baseline prevalence survey in 30 districts. PLoS One. 2016;11:e0162798. 
2. Drudge-Coates $L$, Turner B. Schistosomiasis-an endemic parasitic waterborne disease. Br J Nurs. 2013;22:S10.

3. Kulinkina AV. Community based methods for schistosomiasis prediction and sustainable control in Ghana. PhD dissertation. Tufts University, 2017.

4. King CH. Parasites and poverty: the case of schistosomiasis. Acta Trop. 2010; 113:95-104.

5. Houweling TA, Karim-Kos HE, Kulik MC, Stolk WA, Haagsma JA, Lenk EJ, Richardus JH, de Vlas SJ. Socioeconomic inequalities in neglected tropical diseases: a systematic review. PLoS Negl Trop Dis. 2016;10:e0004546.

6. King $\mathrm{CH}$, Dangerfield-Cha M. The unacknowledged impact of chronic schistosomiasis. Chronic Illn. 2008;4:65-79. https://doi.org/10.1177/ 1742395307084407.

7. Colley DG, Bustinduy AL, Secor WE, King CH. Human schistosomiasis. Lancet. 2014;383:2253-64.

8. Navas ALA, Hamm NA, Magalhães RJS, Stein A. Mapping soil transmitted Helminths and Schistosomiasis under uncertainty: a systematic review and critical appraisal of evidence. PLoS Negl Trop Dis. 2016;10:e0005208.

9. Manyangadze T, Chimbari MJ, Gebreslasie M, Mukaratirwa S. Risk factors and micro-geographical heterogeneity of Schistosoma haematobium in Ndumo area, uMkhanyakude district, KwaZulu-Natal, South Africa. Acta Trop. 2016; 159:176-84. https://doi.org/10.1016/j.actatropica.2016.03.028.

10. Gray DJ, McManus DP, Li Y, Williams GM, Bergquist R, Ross AG. Schistosomiasis elimination: lessons from the past guide the future. Lancet Infect Dis. 2010;10:733-6.

11. Redekop WK, Lenk EJ, Luyendijk M, Fitzpatrick C, Niessen L, Stolk WA, Tediosi F, Rijnsburger AJ, Bakker R, Hontelez JA. The socioeconomic benefit to individuals of achieving the 2020 targets for five preventive chemotherapy neglected tropical diseases. PLoS Negl Trop Dis. 2017;11: e0005289.

12. Mduluza T, Mutapi F. Putting the treatment of paediatric schistosomiasis into context. Infect Dis Poverty. 2017;6:85.

13. Ekpo UF, Oluwole AS, Abe EM, Etta HE, Olamiju F, Mafiana CF. Schistosomiasis in infants and pre-school-aged children in sub-Saharan Africa: implication for control. Parasitology. 2012;139:835-41.

14. Macharia JW, Ng'ang'a ZW, Njenga SM. Factors influencing community participation in control and related operational research for urogenital schistosomiasis and soil-transmitted helminths in rural villages of Kwale County, coastal Kenya. Pan Afr Med J. 2016;24:36. https://doi.org/10.11604/ pamj.2016.24.136.7878

15. Inobaya MT, Olveda RM, Chau TN, Olveda DU, Ross AG. Prevention and control of schistosomiasis: a current perspective. Res Rep Trop Med. 2014; 2014:65.

16. Kabatereine N, Fleming F, Thuo W, Tinkitina B, Tukahebwa EM, Fenwick A. Community perceptions, attitude, practices and treatment seeking behaviour for schistosomiasis in L. Victoria islands in Uganda. BMC Res Notes. 2014;7:900. https://doi.org/10.1186/1756-0500-7-900.

17. Adeneye A, Akinwale O, Idowu E, Adewale B, Manafa O, Sulyman M, Omotola B, Akande D, Mafe M, Appelt B. Sociocultural aspects of mass delivery of praziquantel in schistosomiasis control: the Abeokuta experience. Res Social Adm Pharm. 2007;3:183-98.

18. World Health Organization. Schistosomiasis progress report 2001-2011, strategic plan 2012-2020. Wold Health Organization, Geneva, Switzerland 2013.

19. Jacobstein R, Curtis C, Spieler J, Radloff S. Meeting the need for modern contraception: effective solutions to a pressing global challenge. Int J Gynecol Obstet. 2013;121:S9-15.

20. Amjad UQ, Ojomo E, Downs K, Cronk R, Bartram J. Rethinking sustainability, scaling up, and enabling environment: a framework for their implementation in drinking water supply. Water. 2015;7(4):1497-514

21. Angrist J, and Krueger AB: Instrumental variables and the search for identification: From Supply And Demand To Natural Experiments. Journal of Economic Perspectives, 2001;v15(4,Fall):69-85.

22. Bouchaud JP, Farmer JD, and Lillo F: How markets slowly digest changes in supply and demand. 2008

23. Bowen GA. Grounded theory and sensitizing concepts. Int I Qual Methods. 2006;5(3):12-23.

24. Brinkerhoff JM. Creating an enabling environment for diasporas' participation in homeland development. Int Migr. 2012;50(1):75-95.

25. Svanemyr J, Amin A, Robles OJ, Greene ME. Creating an enabling environment for adolescent sexual and reproductive health: a framework and promising approaches. J Adolesc Health. 2015;56(1):S7-S14.
26. Johnson C: Creating an enabling environment for reducing disaster risk: Recent experience of regulatory frameworks for land, planning and building in low and middle-income countries. Background Paper for the Global Assessment Report on Disaster Risk Reduction 2011, 2011.

27. Downes MJ, Brennan ML, Williams HC, Dean RS. Development of a critical appraisal tool to assess the quality of cross-sectional studies (AXIS). BMJ Open. 2016;6(12):e011458.

28. Anguza J, Oryema-Lalobo M, Oundo G, Nuwaha F. Community perception of intestinal schistosomiasis in Busia district of Uganda. East Afr Med J. 2007;84: 56-66.

29. Dawaki S, Al-Mekhlafi HM, Ithoi I, Ibrahim J, Abdulsalam AM, Ahmed A, Sady $H$, Nasr NA, Atroosh WM. The menace of schistosomiasis in Nigeria: knowledge, attitude, and practices regarding schistosomiasis among rural communities in Kano state. PLoS One. 2015;10:e0143667.

30. Mwai J, Njenga S, Barasa M. Knowledge, attitude and practices in relation to prevention and control of schistosomiasis infection in Mwea Kirinyaga county, Kenya. BMC Public Health. 2016;16:819.

31. Musuva RM, Awiti A, Omedo M, Ogutu M, Secor WE, Montgomery SP, Alaii J, Mwinzi PN. Community knowledge, attitudes and practices on schistosomiasis in western Kenya-the SCORE project. Am J Trop Med Hyg 2014;90:646-52. https://doi.org/10.4269/ajtmh.13-0488.

32. Onyeneho NG, Yinkore P, Egwuage J, Emukah E. Perceptions, attitudes and practices on schistosomiasis in Delta state, Nigeria. Tanzan J Health Res. 2010;12:287-98

33. Rassi C, Kajungu D, Martin S, Arroz J, Tallant J, Zegers de Beyl C, Counihan H, Newell JN, Phillips A, Whitton J, Muloliwa AM, Graham K. Have you heard of Schistosomiasis? Knowledge, attitudes and practices in Nampula Province, Mozambique. PLoS Negl Trop Dis. 2016;10:e0004504. https://doi. org/10.1371/journal.pntd.0004504.

34. Omedo M, Ogutu M, Awiti A, Musuva R, Muchiri G, Montgomery SP, Secor WE, Mwinzi P. The effect of a health communication campaign on compliance with mass drug administration for schistosomiasis control in western Kenya-the SCORE project. Am J Trop Med Hyg. 2014;91:982-8. https://doi.org/10.4269/ajtmh.14-0136.

35. Ng'weng'weta SB, Tarimo DS. Urinary schistosomiasis among preschool-age children in an endemic area of Kinondoni municipality, Dar es Salam, Tanzania 2016. Asian Pac J Trop Dis. 2016;7:162-8.

36. Ekpo UF, Laja-Deile A, Oluwole AS, Sam-Wobo SO, Mafiana CF. Urinary schistosomiasis among preschool children in a rural community near Abeokuta, Nigeria. Parasit Vectors. 2010;3:58. https://doi.org/10.1186/17563305-3-58.

37. Maseko TS, Mkhonta NR, Masuku SK, Dlamini SV, Fan CK: Schistosomiasis knowledge, attitude, practices, and associated factors among primary school children in the Siphofaneni area in the Lowveld of Swaziland. J Microbiol Immunol Infect. 2016. doi:https://doi.org/10.1016/j.jmii.2015.12.003.

38. Mazigo HD, Waihenya R, Mkoji GM, Zinga M, Ambrose EE, Jahanpour $\mathrm{O}$, Bahemana E, Mnyone LL, Kweka EJ, Lwambo NJ. Intestinal schistosomiasis: prevalence, knowledge, attitude and practices among school children in an endemic area of north western Tanzania. J Rural Trop Public Health. 2010;9:53-60.

39. Adoka S, Anyona D, Abuom P, Dida G, Karanja D, Vulule J, Okurut T, Matano A, Gichere S, Ofulla A. Community perceptions of schistosomiasis transmission, prevalence and control in relation to aquatic habitats in the Lake Victoria basin of Kenya. East Afr Med J. 2014;91:232-44.

40. Fleming FM, Fenwick A, Tukahebwa EM, Lubanga RG, Namwangye $H$, Zaramba S, Kabatereine NB. Process evaluation of schistosomiasis control in Uganda, 2003 to 2006: perceptions, attitudes and constraints of a national programme. Parasitology. 2009;136:1759-69. https://doi.org/10.1017/ s0031182009990709.

41. Salawu OT, Odaibo AB. Schistosomiasis transmission; socio-demographic, knowledge and practices as transmission risk factors in pregnant women. J Parasit Dis. 2016;40:93-9. https://doi.org/10.1007/s12639-014-0454-2.

42. Tuhebwe D, Bagonza J, Kiracho EE, Yeka A, Elliott AM, Nuwaha F. Uptake of mass drug administration programme for schistosomiasis control in Koome Islands, Central Uganda. PLoS One. 2015;10:e123673.

43. Mwanga JR, Lwambo NJ. Pre- and post-intervention perceptions and water contact behaviour related to schistosomiasis in north-western Tanzania. Acta Trop. 2013;128:391-8. https://doi.org/10.1016/j.actatropica.2012.09.017.

44. Wolmarans $C T$, De Kock K. The influence of health education on the prevalence, intensity and morbidity of Schistosoma haematobium infections in children over a two-year period in the Limpopo Province, South Africa. S Afr J Epidemiol Infect. 2009;24:13-7. 
45. Chaula SA, Tarimo DS. Impact of praziquantel mass drug administration campaign on prevalence and intensity of Schistosoma haemamtobium among schoolchildren in Bahi district, Tanzania. Tanzan J Health Res. 2014; 16:1-8.

46. Ekpo U, Alabi O, Oluwole A, Sam-Wobo S. Schistosoma haematobium infections in preschool children from two rural communities in ljebu east, south-western Nigeria. J Helminthol. 2012;86:323-8.

47. Omedo MO, Matey EJ, Awiti A, Ogutu M, Alaii J, Karanja DM, Montgomery SP, Secor WE, Mwinzi PN. Community health workers' experiences and perspectives on mass drug administration for Schistosomiasis control in western Kenya: the SCORE project. Am J Trop Med Hyg. 2012;87:1065-72.

48. Odhiambo GO, Musuva RM, Atuncha VO, Mutete ET, Odiere MR, Onyango $\mathrm{RO}$, Alaii JA, Mwinzi PN. Low levels of awareness despite high prevalence of schistosomiasis among communities in Nyalenda informal settlement, Kisumu city, western Kenya. PLoS Negl Trop Dis. 2014;8:e2784. https://doi. org/10.1371/journal.pntd.0002784.

49. Yirenya-Tawiah DR, Annang T, Otchere J, Bentum D, Edoh D, Amoah C, Bosompem K. Urinary schistosomiasis among adults in the Volta Basin of Ghana: prevalence, knowledge and practices. J Trop Med Parasitol. 2011;34: $1-16$.

50. Moyo V, Changadeya W, Chiotha S, Sikawa D. Urinary schistosomiasis among preschool children in Malengachanzi, Nkhotakota District, Malawi: prevalence and risk factors. Malawi Med J. 2016;28:10-4.

51. Yirenya-Tawiah DR, Ackumey MM, Bosompem KM. Knowledge and awareness of genital involvement and reproductive health consequences of urogenital schistosomiasis in endemic communities in Ghana: a crosssectional study. Reprod Health. 2016;13:117.

52. Acka CA, Raso G, N'Goran EK, Tschannen AB, Bogoch II, Séraphin E, Tanner M, Obrist B, Utzinger J. Parasitic worms: knowledge, attitudes, and practices in western Côte d'Ivoire with implications for integrated control. PLoS Negl Trop Dis. 2010;4:e910.

53. Ahmed KS, Siraj NM, Fitsumberhan H, Isaac S, Yohannes S, Eman D, Berhane Y, Araya M. Knowledge, attitude and practice (KAP) assessment of intestinal parasitic infection among school children in Asmara. Eritrea Health. 2016;9: 57.

54. Gyapong JO, Gyapong M, Yellu N, Anakwah K, Amofah G, Bockarie M, Adjei S. Integration of control of neglected tropical diseases into health-care systems: challenges and opportunities. Lancet. 2010;375:160-5.

55. Muhumuza S, Olsen A, Nuwaha F, Katahoire A. Understanding low uptake of mass treatment for intestinal schistosomiasis among school children: a qualitative study in Jinja district, Uganda. J Biosoc Sci. 2015;47:505-20.

56. Person B, Ali SM, A'Kadir FM, Ali JN, Mohammed UA, Mohammed KA, Rollinson D, Knopp S. Community knowledge, perceptions, and practices associated with urogenital schistosomiasis among school-aged children in Zanzibar, United Republic of Tanzania. PLoS Negl Trop Dis. 2016;10: e0004814.

57. Deribe K, Meribo K, Gebre T, Hailu A, Ali A, Aseffa A, Davey G. The burden of neglected tropical diseases in Ethiopia, and opportunities for integrated control and elimination. Parasit Vectors. 2012;5:240.

58. Dabo A, Badawi HM, Bary B, Doumbo OK. Urinary schistosomiasis among preschool-aged children in Sahelian rural communities in Mali. Parasit Vectors. 2011;4:21.

59. Stothard JR, Sousa-Figueiredo JC, Betson M, Bustinduy A, Reinhard-Rupp J. Schistosomiasis in African infants and preschool children: let them now be treated! Trends Parasitol. 2013;29:197-205.

60. Odogwu S, Ramamurthy N, Kabatereine N, Kazibwe F, Tukahebwa E, Webster J, Fenwick A, Stothard J. Schistosoma Mansoni in infants (aged< 3 years) along the Ugandan shoreline of Lake Victoria. Ann Trop Med Parasitol. 2006;100:315-26.

61. Mutapi F, Rujeni N, Bourke C, Mitchell K, Appleby L, Nausch N, Midzi N, Mduluza T. Schistosoma haematobium treatment in 1-5 year old children: safety and efficacy of the antihelminthic drug praziquantel. PLoS Negl Trop Dis. 2011;5:e1143.

62. Hotez PJ, Brindley PJ, Bethony JM, King CH, Pearce EJ, Jacobson J. Helminth infections: the great neglected tropical diseases. J Clin Invest. 2008;1 18:1311.

63. Whittaker M, Berquist R, Buttsworth M. Strengthening control of neglected tropical diseases in the Asia-Pacific region: implications for health information system priorities and strategies. Australia: Health Information Systems, Knowledge Hub, School of Population Health, The University of Queensland; 2013.

\section{Submit your next manuscript to BioMed Central and we will help you at every step:}

- We accept pre-submission inquiries

- Our selector tool helps you to find the most relevant journal

- We provide round the clock customer support

- Convenient online submission

- Thorough peer review

- Inclusion in PubMed and all major indexing services

- Maximum visibility for your research

Submit your manuscript at www.biomedcentral.com/submit
Biomed Central 